\title{
Utilization of oxygen therapy in Mosul
}

Talal Mohammad Saeed Al-sayegh, Mohammad Khalil Ibrahim

Iben-Sina Teaching Hospital, Ninevah Directorate, Mosul

$\frac{\text { Received }}{r 0.1 \cdot Y \cdot 11} \quad \frac{\text { Accepted }}{\Lambda . \Sigma . r \cdot 1 r}$

\section{ABSTRACT}

Objectives:. To document the appropriate way of oxygen utilization therapy for patients admitted in the medical and pediatric wards and to determine whether oxygen therapy as a medicine or not.

Patients and methods: The study involved $1 \cdots$ patients, 11 children and 19 adults, who were receiving oxygen therapy, in different medical and pediatric wards, in IbnSina Teaching Hospital. The youngest patient was $r$ months and the oldest was 10 years. Mean of adult patients $07 . \gamma \pm 17.1$ years while mean of infant $r .0 \pm 1.09$ months . All patients who screened had oxygen apparatus at the bedside, physician orders for oxygen therapy, order of other medical treatment, diagnosis and clinical indication for oxygen therapy and pulse oximetry.

Results: Oxygen therapy was not indicated in $\vee 0 \%$ of the cases, and oxygen was given without supervision during administration, while most other orders of medical therapeutic drugs were written properly and given by pharmacists. Most of the adult patients suffered from respiratory $(\Sigma . \%)$ or cardiac ( $\% \%)$ problems; the remainder ( $\left.\Upsilon^{9 \%} \%\right)$ have other illnesses, $\wedge$ of the children suffered from chest infection.

Conclusion: Oxygen therapy was poorly prescribed and poorly understood and paid less attention compared with other drug therapy.

الخلاصة

هد ف الاراسة: تهاف الدراسة الى توثيق الطريقة المناسبة لاستخدام الاوكسجين للمرضى الر اقدين في ردهات

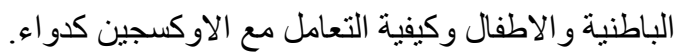

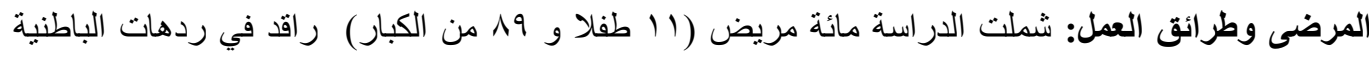

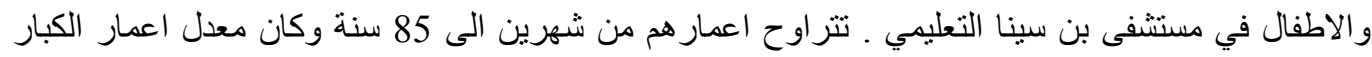

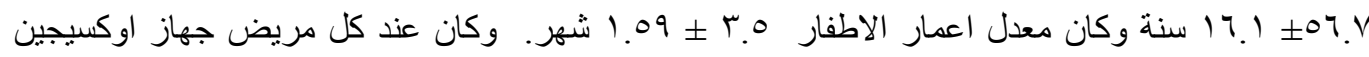

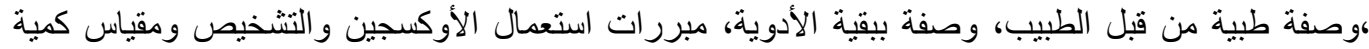

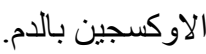

النتائج: تبين أن 75\% من الحالات لا تحتاج الى الأوكسجين وقد أعطي الأوكسجين بدون إشر اف الطبيب خلال

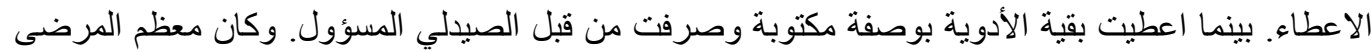

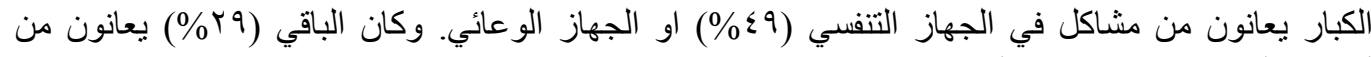

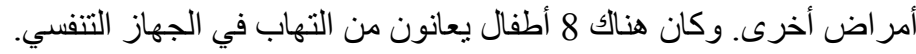

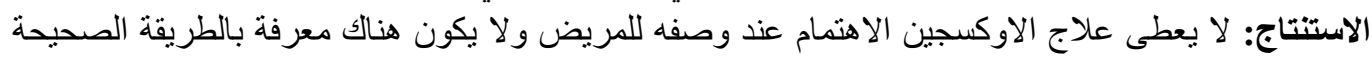
لاعطاءه أسوة ببقية الأدوية.

A though supplemental oxygen clinical situations, excessive or inappropriate supplemental oxygen can be deleterious'. According to human and animal studies, high concentration 
of inspired oxygen can cause a spectrum of lung injury, ranging from mild tracheobronchitis to diffuse alveolar damage (DAD) ${ }^{r, r}$. The latter is histological indistinguishable from that observed in the acute respiratory distress syndrome (ARDS) $)^{r, r}$, as well as extra pulmonary toxicity, the retinopathy of prematurity (previously called retrolental fibroplasia) has been attributed to the toxic effects of oxygen. A cohort study of 1.1 infants demonstrated a significant association between the duration of transcutaneously measured $\mathrm{PaO} r>\Lambda$. $\mathrm{mm} \mathrm{Hg}$ and the incidence and severity of retinopathy ${ }^{\xi}$. Central nervous system symptoms, including generalized tonic-clonic seizures, have been reported secondary to hyperoxia but are unusual in the absence of hyperbaric therapy ${ }^{\varepsilon}$.

Oxygen is prescribed for hypoxemic patients to increase alveolar oxygen tension and decrease the work of breathing; the concentration depends on the condition being treated. Hyperoxia is poorly defined, but probably exists whenever oxygen tension exceeds $r$ \% $\%$ of atmospheric pressure. It appears to produce cellular injury through increased production of reactive oxygen species, such as the superoxide anion, the hydroxyl radical, and hydrogen peroxide ${ }^{\circ}$. If the oxygen saturation is $>9 r \%$, oxygen therapy need not be routinely administered. If the oxygen saturation is $10_{-} 9 \mathrm{r} \%$, oxygen therapy could be initially instituted at $r_{-} r$ liters/min via nasal cannula which would be expected to increase the saturation above $9 r \%$. An oxygen saturation of $<10 \%$ is likely to require higher flows through a simple mask, titrated to achieve a saturation above 9 \%\%. Hypoxia and acidosis are poorly tolerated by the fetus and should be aggressively avoided. From a fetal prospective, it is widely accepted that in non anemic women, maternal POr should be kept at $\geq v$. $\mathrm{mmHg}$ (or at an oxygen saturation of at least $90 \%$ ) to maintain adequate fetal oxygenation .

The oxygen delivery system used in Ibn-Sina Teaching Hospital is compressed gas cylinder which has advantages such as providing highest flow, moderate cost, wide availability and low maintenance. While its disadvantages are heavy weight, and frequent refilling, it must be secured to prevent injury.

Oxygen should be regarded as a drug and should be prescribed by the physician who is responsible for all forms and documentation of oxygen therapy ${ }^{\vee}$. This should include qualifying the arterial blood gas, the type of delivery system to be used (stationary system portable or ambulatory equipment oxygenconserving device and so forth), the delivery device (nasal cannula , transtracheal catheter, mask), the liter flow under specific conditions (sleep, rest, exercise), the patients diagnosis and oxygen saturation $\left(\mathrm{SpO}_{r}\right)^{\wedge}$.

The aim of this study is to assess utilization of oxygen therapy in IbnSina teaching hospital .

\section{Patients and methods}

This study was carried out on 1... patients ( 0 . males and 0 . females) during the period from May to July 
ץ..^, admitted to Ibn-Sina Teaching Hospital in Mosul, ranging in age between $r$ months and ${ }^{1} \circ$ years. History was taken from the included patients regarding presenting complaint, systematic enquiry, medical history, allergy, drug history, alcohol, smoking, family history and social history. Complete physical examination with special attention to clinical manifestations of hypoxemia and hypercapnia (Features of hypoxemia are:-tachycardia, tachypnea, anxiety, diaphoresis, altered mental status, confusion, cyanosis, hypertension, hypotension, bradycardia, seizures, coma. Features of hypercapnia are somnolence, lethargy, restlessness, tremor, slurred speech, headache, asterixis, papilledema, coma, diaphoresis) ${ }^{q}$.

Investigations, diagnosis, and management were received of each patient and the oxygen saturation was measured by pulse-oximetry, during oxygen supplement and $r \cdot-r \cdot$ minutes after cessation of oxygen therapy . Pulse-oximetry is one way to measure the oxygen saturation in blood. Small clip was placed on the finger, toe, earlobe or an infant's foot. This is a simple, convenient, painless way to determine the need for oxygen therapy. In this study, pulse-oximeter v^乏. Kontron was used. The oxygen delivery device, oxygen concentration, and flow rate for each patient were recorded. Consideration whether an oxygen prescription was present regarding the device, concentration, and flow rate and whether the prescription was accurate. The patient was matched need in relation to the delivery device. and whether the flow rate and concentration were appropriate to that device. The following clinical conditions were considered appropriate indications for oxygen therapy such as (cardiac and respiratory arrest, hypoxemia SAOr $<9 . \%$ ), systolic hypotension $(\mathrm{BP}<1 \cdots \mathrm{mm}$ Hg systolic), low cardiac output which evaluated by echocardiography and clinical feature of metabolic acidosis and respiratory distress $(R R>r \varepsilon /$ minute in the adult) '.,' .Assessment also included the dose and method of oxygen administration.

ANOVA test was used to compare measurement between different tested groups. $P<. .0$ were regarded as being statistically significant ${ }^{\top r}$.

\section{Results}

One hundred patients were included in this study. They were ${ }^{\circ}$. male and 0 . female. The youngest patient was ${ }^{r}$ months and the oldest was 10 years. Mean of adult patients $07 . V_{ \pm} / 7$. ' years while mean of infants $r .0 \pm 1.09$ months There were 11 children and 19 adults. In $\vee 0 \%$ of cases, there were no real indication for oxygen therapy $\mathrm{P} \leq . \cdots$ ). The order for giving oxygen was present in $\vee \wedge$ patients $(\vee \wedge \%)$ out of the $\checkmark \wedge$ with written prescription, the order and dose was correct in 7 patients ( $7 \%$ ) of case only. The dose of oxygen was written in 0 . patients $(0 . \%)$ of cases while in $r$ r\% of cases no dose was determined to oxygen. Observations of Vr patients (from indicated or not indicated for oxygen therapy) with incorrectly written order for oxygen revealed the following errors. Firstly, wrong fractional inspired oxygen 
concentration ( $(\mathrm{r} \%)$, secondly, flow meter off (19\%). The order for giving oxygen and dose of oxygen are shown in Table '.

\begin{tabular}{|c|c|c|c|c|}
\hline & & $\begin{array}{l}\text { No. of } \\
\text { patients }\end{array}$ & $\begin{array}{l}\text { Written } \\
\text { order } \\
(\%) \quad \vee \wedge\end{array}$ & $\begin{array}{l}\text { Incorrectly } \\
\text { written order } \\
\text { from } \\
(\%) \text { VY }\end{array}$ \\
\hline \multicolumn{2}{|l|}{ no order } & Tr & 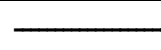 & 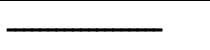 \\
\hline \multirow[b]{2}{*}{ written order } & correct & 7 & $\wedge \%$ & - \\
\hline & Incorrect & $V Y$ & १५\% & _ \\
\hline \multirow[b]{2}{*}{$\begin{array}{l}\text { incorrectly } \\
\text { written } \\
\text { order }\end{array}$} & $\begin{array}{l}\text { oxygen dose } \\
\text { determined }\end{array}$ & 0. & $7 \leqslant \%$ & $V \cdot \%$ \\
\hline & $\begin{array}{l}\text { oxygen dose not } \\
\text { determined }\end{array}$ & TY & ҮА\% & $r \cdot \%$ \\
\hline
\end{tabular}

Table ': Order for giving oxygen and dose of oxygen

Table r: Oxygen delivery devices

\begin{tabular}{|l|l|l|}
\hline Equipments & No. of patients & \multicolumn{1}{c|}{$\%$} \\
\hline Venti- mask & ᄉr & Nr \\
\hline Nasal canula & 10 & 1 \\
\hline Endotracheal tube & 1 & 1 \\
\hline Tracheostomy & 1 & $1 \ldots$ \\
\hline Total & $1 \ldots$ & \\
\hline
\end{tabular}

A variety of delivery devices were used for the delivery of oxygen during this study, most patients incorrectly applied delivery devices ( $\vee \vee \%)$. The delivery devices used are shown in Table r.

Most of the patients suffered from respiratory $(\varepsilon . \%)$ or cardiac ( $\%$ \%) causes the remainder ( $(9 \%)$ from other causes such as leukemia, flaccid paralysis, chronic renal failure, diabetic keto acidosis, status epileptics, stroke, chronic hepatitis.

\section{Discussion}

Although oxygen is beneficial if indicated, it is toxic if used without the presence of hypoxemia't Inhalation of gas mixture with an oxygen flow above $(7 . \%)$ for longer than $\leqslant \wedge$ hours is toxic ${ }^{i r}$. While in the presence of cellular hypoxia sometimes 
oxygen therapy is of great value; however, it is of moderate value, and at still other times, it is of almost no value ". Therefore, it is important to understand the different types of hypoxia, its causes including decrease cardiac output, hypoxemia, anemia, carbon monoxide poisoning and cyanide poisoning','"'. As Blood gas analysis and lactic acid measurement were not available during the study, therefore clinical features of hypoxia, hypercapnia and pulse oximetry were depended.

Most clinical parameters used for indication of oxygen therapy are nonspecific and in the absence of blood gas analysis there will be misuse of oxygen therapy. The order of this study was correct in only $7 \%$ of cases as most of the orders did not mention the duration of oxygen therapy and whether administered continuously or not and errors in fractional inspired oxygen concentration and in flow meter. The dose was correct in $7 \%$ of cases only as most of the order did not contain the flow meter of oxygen and the delivery device, so the dose of oxygen cannot be determined. In other study over $0 . \%$ of hospitalized patients were receiving supplemental oxygen without a written order ${ }^{\prime r}$. Most patients incorrectly applied delivery device such as a mask is loosely fitting over the patient's nose and mouth or obstruction of the air entrapment vents has two consequences, firstly, the oxygen delivered to the mask is not diluted, which leads to a higher than anticipated oxygen flow. Secondly, the total flow of gas to the patient is reduced, which may lead to the re breathing of carbon dioxide. Venturi face masks were used in $\wedge \uparrow \%$ of patients in this study, like other study. Of the commonly used masks, the venturi mask is that most frequently utilized in the general wards of Baragwaneth Hospital, Johannes

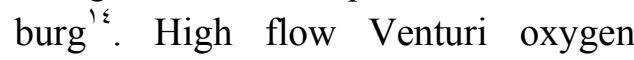
masks yield a precise fraction of inspired oxygen by using of specific valve. The size of the valve aperture ensures that specific proportions of oxygen and entrained air are mixed to obtain a fixed oxygen concentration in quantities that exceed the full ventilator requirement, the correct use of these devices is essential for the avoidance of side effects from this drug $^{10}$.

This study draws the attention to the following points:

oxygen is a drug, like other drugs is always used in optimum dose to obtain the desired effects and avoid unnecessary usage. The aim of therapy is to avoid hypoxia and hyperoxia. Oxygen is given to treat hypoxaemia and ensure adequate arterial oxygenation $\left(\mathrm{SpO}_{\mathrm{r}}>9 . \%\right)^{14}$. The therapeutic goal is to ensure adequate oxygenation of vital organs, the inspired oxygen concentration should be the lowest value that results in adequate arterial saturation $\left(\mathrm{SaO}_{r}\right.$ $>9 . \%)^{1 v}$.

In conclusion that oxygen is provided in medical wards liberally and most oxygen prescriptions are inappropriate, in unregulated fashion and not adequately supervised. Education of medical personnel should stress more prudent prescription and introduction of a prescription chart for 
oxygen therapy with education of patient who need oxygen therapy to deal with oxygen as a medication.

\section{References}

1. Gilbert DL. Oxygen: An overall biological view. In: Oxygen and Living Processes, Gilbert, DL (Ed), Springer-Verlag, New York, 1911;rv7.

r. Jenkinson SG. Oxygen toxicity. New Horiz 199\%; : :0 . .

r. Bitterman H. Bench-to-bedside review: oxygen as a drug. Crit Care r... q; (1):r.0.

£. Flynn JT, Bancalari E, Snyder ES, et al.. A cohort study of transcutaneous oxygen tension and the incidence and severity of retinopathy of prematurity. $\mathrm{N}$ Eng $\mathrm{J}$ Med 199r;rr $7: 1 \cdot 0 \cdot-\varepsilon$.

- Griendling KK, FitzGerald GA. Oxidative stress and cardiovascular injury: Part I: basic mechanisms. and in vivo monitoring of ROS. Circulation $r \ldots r ; 1 \cdot \mu_{0}: 191 r$

7. Dodd M E, Kellet F, Davis A. Audit of oxygen prescribing before and after the introduction of a prescription chart. BMJ

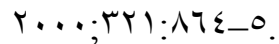

$\vee$. British medical association. British national formulary. Royal Pharmaceutical Society of Great Britain. Y... $;$; Vrro 0 .

$\wedge$. Parsons P, Heffner J. pulmonary/respiratory therapy

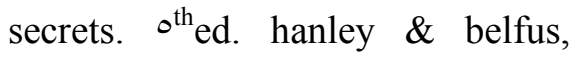
inc./Philadelphia. 199V;1.r_-11.

9. Goldman L, Ausiello D. Cecil Medicine, $r^{\text {rd }}$ ed. Saunders, An Imprint of Elsevier $r \cdots \vee ; p . \vee r \wedge$

1. Costanzo LS. Hypoxemia and Hypoxia. Physiology rrd ed. Elsevier Inc. r..v; p . rr. - rr).

11. Guyton AC, Hall JE. Hypoxia and Oxygen Therapy. Medical physiology. $11^{\text {th }}$ ed. Elsevier Inc. r.. r;p.or.

Ir. Harnis,taylor G. Medical statistic made easy, I $^{\text {st }}$ ed. Washington

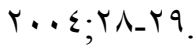

1r. Mowafi AHA. Head of critical care Department .Cairo University, presented as a lecture in Cairo university, Is oxygen inhalation harmful. Y..० April, Cairo, Egypt.

I $\varepsilon$. Fishet AB. Oxygen therapy: side effects and toxicity. Am Rev Respir Dis 191.; Yr:71_-79.

10. Bateman NT, Leach RM. Delivery device of oxegen. BMJ 199人.r. V:V91.

17. Boon NA, Colledge NR, Walker BR. Davidson's Principles and Practice of Medicine. $r^{\text {th }}$ ed. churchill livingstone Elsevier Inc r.. T; 19r-197.

IV. Adrian Sh. Washington Manual of Medical Therapeutics. $\quad$ Ist $^{\text {st }}$. Lippincott Williams \& Wilkins r.. $;$;p $\varepsilon \cdot$ 